\title{
Sol-gel preparation of apatite-coated silica macrospheres from water glass and their adsorption of bovine serum albumin and lysozyme
}

\author{
Jie LI, Yuki SHIROSAKI, Satoshi HAYAKAWA, Artemis STAMBOULIS* and Akiyoshi OSAKA ${ }^{\dagger}$ \\ The Graduate School of Natural Science and Technology, Okayama University, Tsushima, Kita-ku, Okayama 700-8530, Japan \\ *School of Metallurgy and Materials, University of Birmingham, Edgbaston, Birmingham B15 2TT, UK
}

\begin{abstract}
Silica gel macrospheres were prepared from water glass as the silica source. The water glass solution was mixed with sodium alginate solution and added dropwisely to $1 \mathrm{M} \mathrm{CaCl}_{2}$ solution to form macrospheres with $\sim 4$ and $2.6 \mathrm{~mm}$ in diameter. $\mathrm{Those} \mathrm{SiO}_{2}$ macrospheres were soaked in 1:1 (volume) mixture of ethanol and $0.1 \mathrm{M} \mathrm{Na}_{2} \mathrm{HPO}_{4}$ to deposit hydroxyapatite layer $\left(\mathrm{HAp}^{-S i O} \mathrm{O}_{2}\right.$ macrospheres). Bovine serum albumin (BSA) and egg lysozyme (LYZ) were adsorbed those $\mathrm{SiO}_{2}$ and $\mathrm{HAp}_{-} \mathrm{SiO}_{2}$ macrospheres. The amount of proteins adsorbed was well correlated to the Langmuir-type adsorption equation. The electrostatic interaction was predominant between the macrosphere surface and the protein molecules. Protein molecular entrapment in the mesopores (5$25 \mathrm{~nm}$ ) was also probable for the $\mathrm{SiO}_{2}$ macrospheres but not applicable to the $\mathrm{HAp}_{-\mathrm{SiO}}$ ones without the mesopores. From consideration that protein molecule has a few groups with negative or positive partial charges, a multi-layer adsorption model was proposed.
\end{abstract}

(C2012 The Ceramic Society of Japan. All rights reserved.

Key-words : Silica macrospheres, Sol-gel processing, Apatite deposition, Protein adsorption, Microstructure

\section{Introduction}

Blood compatible adsorbents find various biomedical applications, such as medical implants, ${ }^{1)-3)}$ biodiagnostics, ${ }^{4)}$ targeted drug delivery, ${ }^{5), 6)}$ biosensors and devices, ${ }^{7-9)}$ and blood purification or hemoperfusion. ${ }^{10)-14)}$ Apatite is one of such adsorbents and is employed for chromatographic separation of serum proteins. ${ }^{15-18)}$ Because of their high tissue compatibility, non-inflammation, and non-immunogenesis, ${ }^{19)}$ hydroxyapatite [HAp; $\mathrm{Ca}_{10^{-}}$ $\left.\left(\mathrm{PO}_{4}\right)_{6}(\mathrm{OH})_{2}\right]$ and ion-substituted non-stoichiometric apatite particles are also employable to remove pathogenic substances. For example, Takashima et al. ${ }^{20}$ confirmed good blood compatibility of a few non-stoichiometric hydroxyapatite, and showed better adsorption of $\beta_{2}$-microglobulin $\left(\beta_{2}\right.$-MG) than that of bovine serum albumin (BSA). Fujii et al. ${ }^{21)}$ and Hayakawa et al. ${ }^{22)}$ studied the selective adsorption of $\beta_{2}$-MG and BSA on zincsubstituted hydroxyapatite as a function of the $\mathrm{Zn}$ content and $\mathrm{Zn}$ distribution in the apatite particles. Takemoto et al. ${ }^{23)}$ synthesized hydroxy-carbonate apatite and showed that a larger carbonate ion content was responsible for better selectivity of $\beta_{2}$-MG.

Adsorbent materials for biological applications have been prepared in various forms such as membranes, ${ }^{24), 25)}$ fibers, ${ }^{26)}$ sheets, ${ }^{27)}$ nano- or microparticles, ${ }^{28)}$ and consist of organic, inorganic, or hybrid components: polymers (resins), ${ }^{29)}$ ceramic materials such as titania ${ }^{13)}$ and hydroxyapatite, ${ }^{30)}$ metal granules, ${ }^{31)}$ amorphous graphitic or fullerene-like carbon nitride, ${ }^{32)}$ or porous silicates. ${ }^{33), 34)}$ For blood purification clinics like hemoperfusion and dialysis including peritoneal dialysis, packed columns of macrospheres or suspension of macrospheres with $\mathrm{mm}$ in size would be advantageous because the macrospheres in

\footnotetext{
Corresponding author: A. Osaka; E-mail: a-osaka@cc.okayama-u. ac.jp
}

that size range are more convenient in handling and easier to control quantity. Moreover, one may avoid least risk that their fragments are carried into blood vessel.

Since the adsorption takes place at the interface between the material and surrounding moiety involving adsorbates, the most important factors for optimizing the adsorbents include the particle size (surface area and curvature), surface charge density, crystallography, and surface morphology, while the pore size and its distribution are also predominant factors if the adsorbates are able to be trapped in the pores. Moreover, the adsorbents in the form of fine particles set in hemoperfusion blood purification columns might introduce any diverse problems when they are in contact with flowing blood or blood plasma and some might be released in the flow. Fixing those active adsorbents on some neutral substrates to form a core-shell architecture can avoid those problems with preserving their adsorbing ability.

When the fabrication cost is taken into account, silica is the best substrate among possible candidates, like polymers, active carbon, chemically stable ceramics, or composites. Flexible fabrication of silica would rely on the sol-gel synthesis procedure with which the particles of any shape and size are produced and various surface modifications are possible. Silica gel has been studied extensively in the past four decades where hydrolysis of alkoxysilanes and condensation of the resulted silanol groups under acid or basis catalysis are the primary topics. More feasible source of $\mathrm{Si}(\mathrm{IV})$ is water glass, or highly hydrolyzed sodium disilicate, because of its commercial availability. After use in hemoperfusion or blood purification, the adsorbent silica particles could be abandoned after calcining or sterilization. Moreover, securing blood or plasma flow under least pressure needs mmsized spheres packed in about a few hundred $\mathrm{ml}$ of column volumes. The fabrication of the silica substrates must be highly cost-oriented. 
Silica gel granules are commercially available since long as a drying agent, and they are good candidates as the substrates for such applications. However, their dry surface must be appropriately hydrolyzed by the treatment with acid or alkaline solutions to fix an active layer. Studies of such hydrolysis and adsorbent coating are under way, and the results will be later presented elsewhere. In the present study, a convenient sol-gel approach was developed to prepare silica macrospheres $(\sim 2 \mathrm{~mm}$ in wet states) on which an apatite layer was deposited via the procedure similar to glass-apatite conversion, provided by Rahman, Day, and co-workers. ${ }^{35)}$ The microstructure of the gel spheres and surface morphology were characterized. Adsorption of model proteins, bovine serum albumin (BSA) and egg lysozyme (LYZ), was analyzed and the mechanism of adsorption was discussed.

\section{Experimental}

\subsection{Preparation of silica macrospheres and apa- tite deposition}

\subsubsection{Silica gel macrospheres}

Water glass, purchased from nacalai tesque, Osaka, Japan, involved 55 mass $\%$ sodium disilicate, $\mathrm{Na}_{2} \mathrm{O} \cdot 2 \mathrm{SiO}_{2}$, after a chemical analysis. Distilled water was added to the original solution to obtain 30 mass $\%$ water glass solution. Then, gelation time $\left(\mathrm{t}_{\mathrm{gel}}\right)$ of the silicate solutions with varied $\mathrm{pH}$ in the range $2-10.5$ were examined as described later in $\S 3$. With its enough long $\mathrm{t}_{\mathrm{gel}}$, the silicate solution of $\mathrm{pH} 3$ was employed in the following experiments.

The silicate solution of $\mathrm{pH} 3$ was mixed with 1.5 mass $\%$ sodium alginate solution in the mass ratio $2: 3$ under stirring. $t_{\text {gel }}$ for this mixture was about $85 \mathrm{~min}$. The silicate-alginate mixture of $12 \mathrm{ml}$ was immediately added dropwisely to $50 \mathrm{ml} 1 \mathrm{M} \mathrm{CaCl}_{2}$ solution ( $\mathrm{pH} \mathrm{4.8)} \mathrm{at} \mathrm{a} \mathrm{rate} \mathrm{of} 0.3 \mathrm{ml} / \mathrm{min}$, using a syringe feeder through a needle (the inner diameter: $0.8 \mathrm{~mm}$ ), to yield approximately 800 macrospheres. These macrospheres were aged for $1 \mathrm{~d}$ at $40^{\circ} \mathrm{C}$ in the $\mathrm{CaCl}_{2}$ solution. Here, the $\mathrm{CaCl}_{2}$ solution contained a highly excess amount of calcium ions over the stoichiometric amount necessary for the alginate molecules to form Ca-alginate chelate. All of those $\sim 800$ macrospheres were subsequently soaked in $40 \mathrm{ml} 0.1 \mathrm{M} \mathrm{NH}_{4} \mathrm{OH}$ solution $(\mathrm{pH} \mathrm{9.7)} \mathrm{for} 1 \mathrm{~d}$ at $25^{\circ} \mathrm{C}$. The final $\mathrm{pH}$ of the ammonia solution was $\sim 8.5$. Those wet Ca-silica macrospheres were washed in $100 \mathrm{ml}$ distilled water for 10 min under gentle stirring. This procedure was iterated for 3 times to obtain wet Ca-silica macrospheres.

About $2 \mathrm{~g}$ of wet macrospheres were used to examine silica content: they were washed with distilled water to drive off free sodium and calcium ions, freeze-dried, and then subjected to heating at $800^{\circ} \mathrm{C}$ for $1 \mathrm{~h}$ in air. The silica content in the wet gel was 7.6 mass $\%$, while the freeze-dried macrospheres consisted of $\sim 71.5$ mass $\% \mathrm{SiO}_{2}, 17.4$ mass \% organic component or alginate, and 10.8 mass $\% \mathrm{H}_{2} \mathrm{O}$ held in closed pores. The silica content in the calcined body was 99.6 mass \% with amount of calcium ions in the calcined was negligibly small $\mathrm{CaO}$ content $(\sim 0.4$ mass $\%)$.

\subsubsection{HAp-coating on silica macrospheres (HAp- $\mathrm{SiO}_{2}$ )}

The as-washed Ca-silica gel macrospheres were placed in a tightly capped polystyrene bottle $(50 \mathrm{ml})$ together with $40 \mathrm{ml}$ of a 1:1 (volume) mixture of ethanol and $0.1 \mathrm{M} \mathrm{Na}_{2} \mathrm{HPO}_{4}$. The volume ratio of the spheres vs. the mixture was set at $\sim 1: 7$. The bottles were then kept in an oven at $80^{\circ} \mathrm{C}$ for $1 \mathrm{~d}$. During the incubation, it is expected that the phosphate ions took out the calcium ions from the Ca-alginate chelate molecules in the $\mathrm{SiO}_{2}$ macrospheres to yield apatite via the reactions similar to the glass-apatite conversion. ${ }^{35)}$

$$
\begin{aligned}
& \mathrm{Ca}^{2+}\left(\mathrm{Ca} \text {-alginate chelate molecules } / \mathrm{SiO}_{2}\right) \\
& +\mathrm{HPO}_{4}{ }^{2-}+\mathrm{OH}^{-} \\
& \quad \rightarrow \mathrm{Ca}_{5}\left(\mathrm{PO}_{4}\right)_{3} \mathrm{OH}+\text { alginate molecules }
\end{aligned}
$$

To stabilize the free alginate molecules, those macrospheres were soaked again in the $1 \mathrm{M} \mathrm{CaCl}_{2}$ solution for $30 \mathrm{~min}$. Then, those $\mathrm{HAp}-\mathrm{SiO}_{2}$ macrospheres were rinsed with distilled water three times as above described, dried in an oven overnight, and stored in a desiccator until use.

\subsection{Characterization}

\subsubsection{Microstructure analyses}

$\mathrm{X}$-ray powder diffraction (XRD) was taken for the freeze-dried $\mathrm{HAp}-\mathrm{SiO}_{2}$ macrospheres to identify the deposited phase: $\mathrm{Cu} \mathrm{K} \alpha_{1}$; an Ultima IV machine (Rigaku, Tokyo, Japan), operated at $40 \mathrm{kV}$ and $40 \mathrm{~mA}, \theta / 2 \theta$ step-scanned with a $0.02^{\circ}$ step in the $2 \theta$ range $10-70^{\circ}$, and holding time of $1 \mathrm{~s}$ per step. Surface microstructure of the macrospheres was observed under a scanning electron microscope (SEM; DS720, TOPCON, Tokyo, Japan: $20 \mathrm{kV}$ acceleration), equipped with an Energy dispersion X-ray (EDX) analyzer with which the presence of component atoms was to be confirmed. Fourier-Transform Infrared (FT-IR) spectra of the macrospheres were also measured using the $\mathrm{KBr}$ method where $2 \mathrm{mg}$ dry samples were shaped into discs together with $200 \mathrm{mg} \mathrm{KBr}$ (Nicolet, Nexus 470TH, Thermo Scientific, Yokohama, Japan). Crush resistance and strain at failure of the silica gel macrospheres were measured using a Rheoner RE-33005 machine (Yamaden, Osaka, Japan) with the strain rate of $0.5 \mathrm{~mm} / \mathrm{s}$. After dried in vacuuo, pore size distribution and specific surface area were derived from the nitrogen adsorption and B.E.T. analysis (Gemini 2360, Micromeritics, Osaka, Japan). Particle sizes were measured under an optical microscope, equipped with an image analyzing software.

\subsubsection{Protein adsorption}

Human serum contains $30-50 \mathrm{mg} / \mathrm{ml}(450-750 \mu \mathrm{mol} / \mathrm{L})$ albumin but only a trace amount $4-11 \mu \mathrm{g} / \mathrm{ml}(0.27-0.75 \mu \mathrm{mol} / \mathrm{L})$ of LYZ. Albumin and lysozyme are typical acidic and basic proteins, and they are negatively and positively charged, respectively, under physiological conditions. They are then good model proteins for which the adsorbent capability is to be evaluated, because the adsorption is frequently interpreted in terms of the electrostatic interactions between the adsorbents and the relevant proteins. The present study employed bovine serum albumin (BSA) and egg lysozyme (LYZ): molecular weight (Mw) of BSA is about $67200 \mathrm{D}$ while that of LYZ is $14600 \mathrm{D}$, and their sizes are about $4 \times 4 \times 16 \mathrm{~nm}$ and $3 \times 3 \times 4.5 \mathrm{~nm}$, respectively. Both were purchased from Wako Chemical, Osaka, Japan, and used without further purification for the adsorption experiments. They were dissolved into saline to attain solutions of concentration up to $10 \mathrm{mg} / \mathrm{ml}$ or $2.0 \mathrm{mM}$, and their $\mathrm{pH}$ was adjusted to 7.4 using tris(hydroxymethyl)aminomethane (TRIS) buffer. The macrospheres $(\sim 0.2 \mathrm{~g}$ in dry weight) and $5 \mathrm{ml}$ BSA or LYZ solutions were placed in tightly capped $5 \mathrm{ml}$ glass bottles, mounted on a thermostatic shaking-bath, and the bottles were shook at $2 \mathrm{~Hz}$ at $37^{\circ} \mathrm{C}$ for $0-300 \mathrm{~min}$. After filtering out the macrospheres, the amount of residual proteins in the protein solutions was measured photometrically, ${ }^{10), 20)}$ using a UV-Visible spectrophotometer (UV-2550, Shimadzu, Kyoto, Japan), assuming that the optical density of the peaks around 280 and $270 \mathrm{~nm}$ was proportional to the amount of BSA and LYZ, respectively. The adsorption data were fitted with Langmuir-type adsorption isotherm.

$$
\Gamma=\Gamma_{\max } K c /(1+K c)
$$



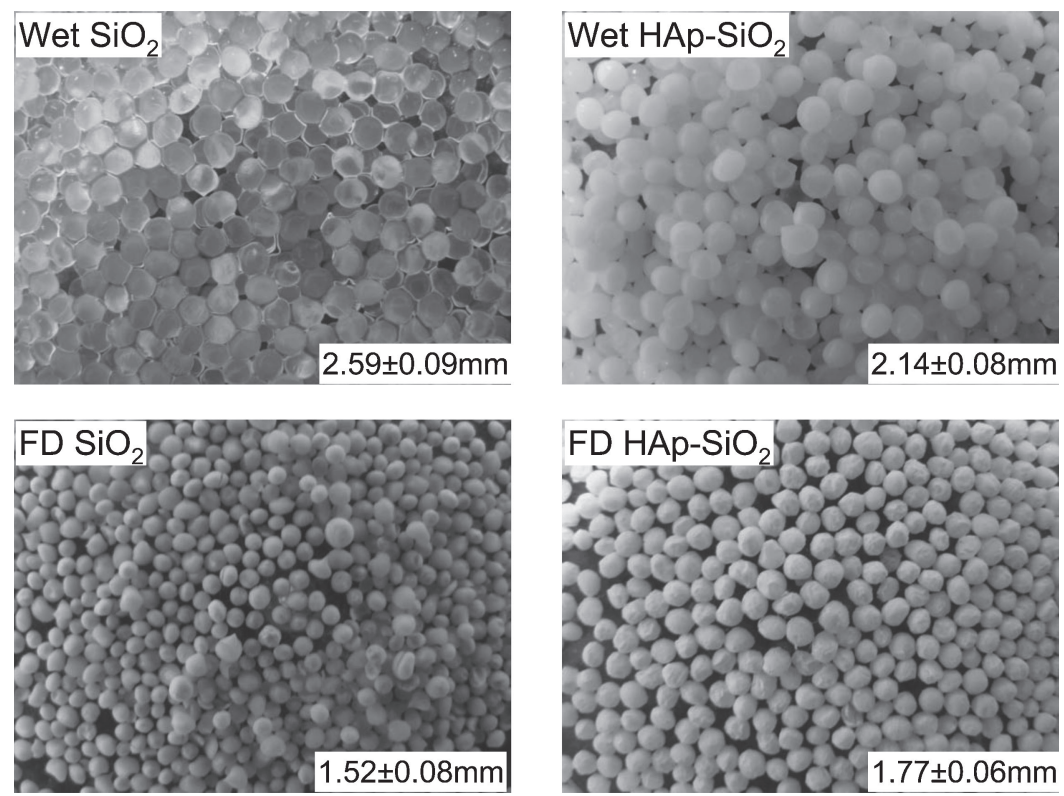

Fig. 1. Optical photo images of the $\mathrm{SiO}_{2}$ and $\mathrm{HAp}-\mathrm{SiO}_{2}$ macrospheres. Wet: as-prepared, FD: freeze-dried. Their average size is indicated in each frame.

Here, $\Gamma$ is the amount of protein adsorbed on the macrospheres in equilibrium with the protein concentration $c, \Gamma_{\max }$ stands for the maximum adsorption where all of the active sites are occupied by the adsorbate molecules. $K$ is the constant related to the rate constants of adsorption and desorption. The original Langmuir equation was derived for gas adsorption under several assumptions. Equation (2) has been sometimes applied to other cases, like the protein adsorption. Rearranging Eq. (2) leads to Eq. (3):

$$
1 / \Gamma=\left(1 / \Gamma_{\mathrm{m}}\right)+\left(1 / \Gamma_{\mathrm{m}} \cdot K\right)(1 / c)
$$

If the adsorption data are plotted to correlate $1 / \Gamma$ to $1 / c$ and a linear relation is obtained, the parameters in Eqs. (2) or (3) will be given for discussion.

\section{Results}

\subsection{Macrospheres}

Gelation time $\left(\mathrm{t}_{\mathrm{gel}}\right)$ of the silicate solution without alginate was obtained as a function of $\mathrm{pH}$, since $t_{\text {gel }}$ was a measure of stability of the present water glass sol/gel system and determined the workability. $\mathrm{t}_{\mathrm{gel}}$ showed a U-letter shaped dependence on $\mathrm{pH}$. An alkoxide system $\mathrm{Si}\left(\mathrm{OC}_{2} \mathrm{H}_{5}\right)_{4}-\mathrm{H}_{2} \mathrm{O}-\mathrm{C}_{2} \mathrm{H}_{5} \mathrm{OH}-\mathrm{H}_{2} \mathrm{O}$ [the molar ratio $\mathrm{Si}\left(\mathrm{OC}_{2} \mathrm{H}_{5}\right)_{4} / \mathrm{H}_{2} \mathrm{O}=4$ ] showed a similar $\mathrm{t}_{\text {gel }}$ dependence on $\mathrm{pH}^{36)}$ In the range $\mathrm{pH}<3$, $\mathrm{t}_{\text {gel }}$ was substantially long, $\sim 1000$ min or longer. The silicate solution of $\mathrm{pH} 3$ showed $\mathrm{t}_{\mathrm{gel}} \sim 40 \mathrm{~min}$ and was transparent-little opaque when prepared. The opacity increased with the aging and a slight amount of supernatant was detected on the top of the solution body, indicating syneresis due to gelation. In the range $\mathrm{pH} 3$ through 9.5 , the system gelled very quickly within $<15 \mathrm{~min}$. When $\mathrm{pH}$ exceeded 9.5 , the silicate solution looked milky already when prepared, and sedimentation on the container bottom was found when held for $1 \mathrm{~d}$ at $25^{\circ} \mathrm{C}$. Moreover, mixing alginate elongated $t_{\text {gel }}$ for the silicate solution of $\mathrm{pH} 3$ to $\sim 85 \mathrm{~min}$, and hence, this solution in the range $\mathrm{pH}=3$ was concluded optimum for the macrosphere fabrication.

The feeding rate of the silicate solution controlled the size of the silica macrospheres, ranging from $\sim 4$ to $\sim 1 \mathrm{~mm}$ in diameter. Figure 1 shows typical wet silica gel macrospheres of $2.6 \mathrm{~mm}$ in diameter. The size decreased a little with the apatite deposition: from 2.6 to $2.1 \mathrm{~mm}$, while the freeze-drying procedure naturally shrunk the $\mathrm{SiO}_{2}$ macrospheres by $\sim 40 \%$ and the $\mathrm{HAp}-\mathrm{SiO}_{2}$ ones by $\sim 20 \%$. The both wet macrospheres bounced when dropped from $\sim 5 \mathrm{~cm}$ in height, but the dry ones behaved like ceramics, or they were brittle. The force and apparent strain at collapse were measured as a function of the period of aging in the $1 \mathrm{M} \mathrm{CaCl}_{2}$ solution. The as-prepared macrospheres, or wet $\mathrm{SiO}_{2}$ in Fig. 1, collapsed at $27 \mathrm{~g} \cdot \mathrm{f}$ ( or $0.26 \mathrm{~N}$ ), and those aged for $\sim 3 \mathrm{~h}$ were broken at $38 \mathrm{~g} \cdot \mathrm{f}(0.37 \mathrm{~N})$, whereas those aged for $12 \mathrm{~h}$ or longer collapsed at $\sim 47 \mathrm{~g} \cdot \mathrm{f}(0.46 \mathrm{~N})$. For the aging within 1 day, the apparent strain (diameter at collapse/diameter before the force being loaded) decreased slightly from $\sim 62$ to $58 \%$, or remained almost constant. Not only the silica network development due to gelation but also reinforcement with the Ca-alg chelate formation supposedly were effective for strengthening the gel macrospheres, and they were strong enough to be handled with tweezers for removal or transport.

The XRD patterns for the dry $\mathrm{HAp}-\mathrm{SiO}_{2}$ in Fig. 2 show the diffraction peaks of hydroxyapatite (JCPDS 9-0432), and their intensity increased slightly with aging in the ethanol/ $\mathrm{Na}_{2} \mathrm{HPO}_{4}$ solution. The XRD profile for the $\mathrm{SiO}_{2}$ macrosphere at the bottom indicated no detectable peaks assignable to $\mathrm{NaCl}, \mathrm{CaCl}_{2}$ or other possible ingredients. This might indicate the absence of sodium and chloride ions in the system. Yet, one should examine the EDX profiles before giving definite remarks because the possibility remained that their weak diffractions were masked by the XRD signal noise. Note that the peak width at half height maximum was almost independent of the aging period, $\sim 0.38^{\circ}$ in $2 \theta$, and the aging longer than $3 \mathrm{~h}$ indicated no further increase in the diffraction intensity.

Figure 3 shows the FT-IR spectra of the $\mathrm{SiO}_{2}$ macrospheres after aged under different conditions and those of $\mathrm{HAp}-\mathrm{SiO}_{2}$ ones, where the bands have been assigned according to the literatures. ${ }^{37)-39)}$ A broader band $v_{\mathrm{s}}(\mathrm{O}-\mathrm{H})$ of the residual $\mathrm{H}_{2} \mathrm{O}$ was detected around $3430 \mathrm{~cm}^{-1}$, while the strong one, denoted as $\nu$ (Si-O,P-O), around 1080 or $1101 \mathrm{~cm}^{-1}$ with a shoulder $\left(\sim 1200 \mathrm{~cm}^{-1}\right)$ was the $\nu_{3}(\mathrm{Si}-\mathrm{O})$ band superimposed with the $v_{3}\left(\mathrm{PO}_{4}{ }^{3-}\right)$ band. The two bands at 804 and $468 \mathrm{~cm}^{-1}$ in the low 
energy region were assigned to $v_{1}\left(\mathrm{SiO}_{4}\right)$ and $\delta(\mathrm{Si}-\mathrm{O})$. The $v_{1}$ mode of the $\mathrm{SiO}_{4}$ tetrahedron, belonging to representation $\mathrm{A}_{1}$, is only Raman active, but sometimes the $\sim 800 \mathrm{~cm}^{-1}$ IR band has been assigned to this mode. The 964 and $563 \mathrm{~cm}^{-1}$ bands were assigned to the $v_{1}$ and $v_{4}$ modes of the orthophosphate ions. It is reasonable that those phosphate bands were detected only for the $\mathrm{HAp}-\mathrm{SiO}_{2}$ macrosphere. In addition, the $v_{\text {as }}$ and $v_{\mathrm{s}}$ modes of the carboxyl groups of alginate were found at 1625 and 1423 $\mathrm{cm}^{-1}$ for both $\mathrm{SiO}_{2}$ and $\mathrm{HAp}-\mathrm{SiO}_{2}$, indicating that the alginate molecules remained in the gel spheres.

The SEM images in Fig. 4 compare the surface microstructures of (a) $\mathrm{SiO}_{2}$ and (c) $\mathrm{HAp}-\mathrm{SiO}_{2}$. The EDX signals from their surface were presented in (b) and (d), respectively. The $\mathrm{SiO}_{2}$ macrospheres had smoother surface, while flaky crystallites covered the HAp- $\mathrm{SiO}_{2}$ surface. Those crystallites were apatite according to the XRD in Fig. 3. Predominant EDX signals were due to Si and $\mathrm{O}$ in both spectra (b) and (d). The Ca peak in (b) was attributed to the presence of Ca-alginate chelate molecules. The peak for $\mathrm{P}$ was detected only in (d) in agreement with the apatite deposition, indicated by the SEM image (c) and the XRD

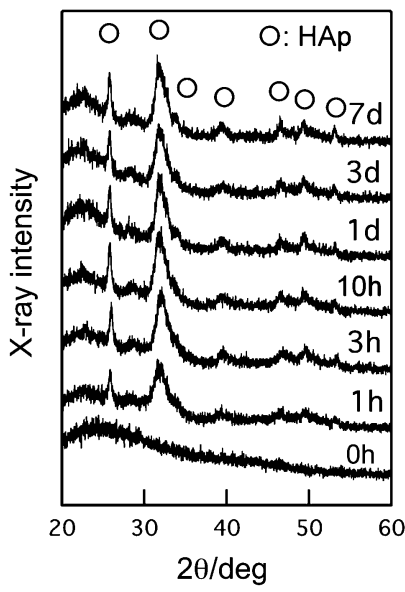

Fig. 2. XRD patterns of the $\mathrm{SiO}_{2}$ macrospheres after HAp-coating by soaking them in the $1: 1$ (vol/vol) mixture of ethanol/0.1 $\mathrm{M} \mathrm{Na}_{2} \mathrm{HPO}_{4}$ at $80^{\circ} \mathrm{C}$ for $1 \mathrm{~h}-7 \mathrm{~d}$. profile in Fig. 2. In addition, the peaks of $\mathrm{Na}$ and $\mathrm{Cl}$, though trace, were detected in both (b) and (c), indicating that the sodium ions were not thoroughly washed away from the macrospheres.

Pore size distribution profiles in Fig. 5 for $\mathrm{SiO}_{2}$ macrospheres showed a sharp peak at $\sim 3 \mathrm{~nm}$, and a broad peak in the mesopore region, extending from 5 to $20 \mathrm{~nm}$. In contrast, the mesopores seemed to disappear due to the HAp-coating, leaving the peak at $\sim 3 \mathrm{~nm}$. Specific surface area (SSA) data were also derived from the $\mathrm{N}_{2}$ adsorption experiment: 220 and $173 \mathrm{~m}^{2} / \mathrm{g}$ for $\mathrm{SiO}_{2}$ and $\mathrm{HAp}-\mathrm{SiO}_{2}$ macrospheres, respectively, as listed in Table 1 together with some other properties characteristic of the protein adsorption.

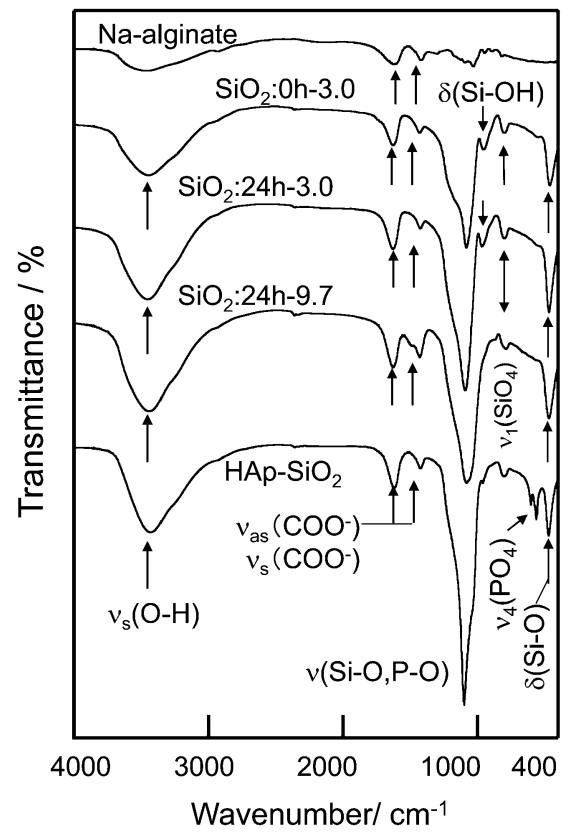

Fig. 3. The FT-IR spectra of $\mathrm{SiO}_{2}$ and $\mathrm{HAp}-\mathrm{SiO}_{2}$ macrospheres together with the spectrum of sodium alginate as a reference. The aging time in the solutions of $\mathrm{pH} 3.0$ and 9.7 for the $\mathrm{SiO}_{2}$ macrospheres was indicated like $\mathrm{SiO}_{2}: 24 \mathrm{~h}-3.0$. Some bands characteristic of each unit or group were presented with arrows.
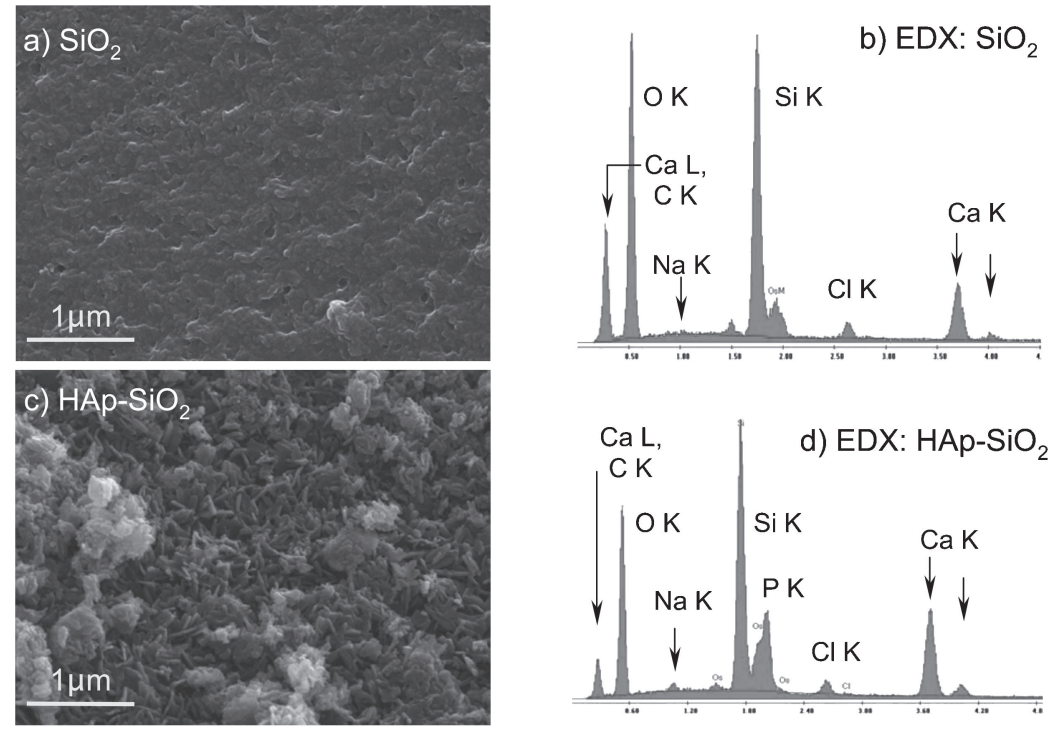

Fig. 4. SEM images (a, c) and EDX point analysis (b, d) for the $\mathrm{SiO}_{2}(\mathrm{a}, \mathrm{b})$ and $\mathrm{HAp}-\mathrm{SiO}_{2}(\mathrm{c}, \mathrm{d})$ macrospheres. The EDX peaks were assigned to the component atoms. 


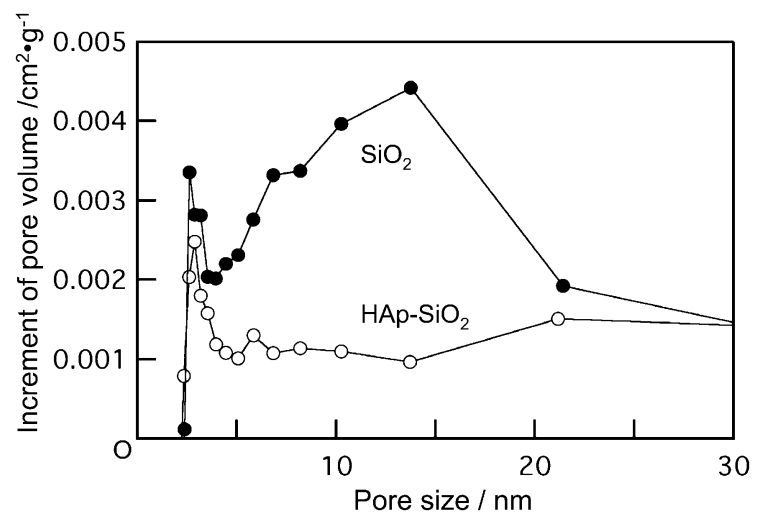

Fig. 5. The pore size distribution of the $\mathrm{SiO}_{2}$ and $\mathrm{HAp}-\mathrm{SiO}_{2}$ macrospheres.

Table 1. Size, SSA, and some Langmuir isotherm constants for BSA and $\mathrm{LYZ}$ adsorption for $\mathrm{SiO}_{2}$ and $\mathrm{HAp}-\mathrm{SiO}_{2}$ macrospheres

\begin{tabular}{lcccccc}
\hline & $\begin{array}{c}\mathrm{Size}^{\mathrm{a})} \\
(\mathrm{mm})\end{array}$ & $\begin{array}{c}\mathrm{SSA} \\
\left(\mathrm{m}^{2} / \mathrm{g}\right)\end{array}$ & $\begin{array}{c}\Gamma_{\mathrm{m}}{ }^{\mathrm{b})} \\
\left(\mu \mathrm{g} / \mathrm{m}^{2}\right)\end{array}$ & $\begin{array}{c}\mathrm{K}^{\mathrm{b})} \\
(\mathrm{L} / \mathrm{mg})\end{array}$ & $\begin{array}{c}\theta^{\mathrm{c})} \\
(-)\end{array}$ & $\begin{array}{c}\Gamma_{\mathrm{m}}{ }^{\mathrm{d})} \\
\left(\mathrm{n} \mathrm{mol} / \mathrm{m}^{2}\right)\end{array}$ \\
\hline $\mathrm{SiO}_{2}$ & 1.52 & 220 & $26 .(\mathrm{B})^{\mathrm{e})}$ & $0.20_{3}(\mathrm{~B})$ & $0.013(\mathrm{~B})$ & $0.4(\mathrm{~B})$ \\
& & & $476 .(\mathrm{L})$ & $0.30_{0}(\mathrm{~L})$ & $0.206(\mathrm{~L})$ & $32 .{ }_{6}(\mathrm{~L})$ \\
$\mathrm{HAp}-\mathrm{SiO}_{2}$ & \multirow{2}{*}{1.77} & \multirow{2}{*}{173} & 400. (B) & $0.09_{1}(\mathrm{~B})$ & $0.201(\mathrm{~B})$ & $6.0(\mathrm{~B})$ \\
& & & 1667. (L) & $0.66_{7}(\mathrm{~L})$ & $0.722(\mathrm{~L})$ & $114.2(\mathrm{~L})$ \\
\hline
\end{tabular}

a) Average diameter of the freeze-dried macrospheres.

b) Eq. (3).

c) Eq. (4). Molar weight of BSA and LYZ: $67200 \mathrm{D}$ and 14600D; molecular size: BSA $4 \times 14 \mathrm{~nm}$, LYZ $3 \times 3.5 \mathrm{~nm}$ (Ref. 26).

d) $\Gamma_{\mathrm{m}}$ in molar basis.

e) B: BSA, L: LYZ.

\subsection{Protein adsorption}

Figure 6 shows that BSA and $\mathrm{LYZ}$ adsorption on the $\mathrm{SiO}_{2}$ and $\mathrm{HAp}-\mathrm{SiO}_{2}$ macrospheres was dependent not only on the contact time but also on the protein concentrations of the solutions. Although similar adsorption profiles were obtained also for the $\mathrm{SiO}_{2}$ macrospheres, the data only for the $10 \mathrm{mg} / \mathrm{ml} \mathrm{BSA}$ and LYZ solution were presented in Fig. 6, for avoiding clutter. Figure 6(a) indicates that BSA adsorption on both macrospheres increased rapidly but it reached an equilibrium state for any concentration within $100 \mathrm{~min}$. The equilibrium adsorption increased with the BSA content of the solutions. In Fig. 6(b), LYZ showed more vigorous adsorption since the beginning, and reached their equilibrium adsorption $\sim 80$ min for the $\mathrm{HAp}-\mathrm{SiO}_{2}$ macrospheres, but it took longer for the $\mathrm{SiO}_{2}$ ones. It follows that both macrospheres adsorbed several times as much LYZ as BSA: for example, $800 \mu \mathrm{g} / \mathrm{m}^{2} \mathrm{LYZ}$ but only $120 \mu \mathrm{g} / \mathrm{m}^{2}$ BSA were adsorbed on $\mathrm{HAp}-\mathrm{SiO}_{2}$.

\section{Discussion}

\subsection{Growth of the Si-O IR band}

It is noticeable in the IR spectra in Fig. 3 of $\mathrm{SiO}_{2}: 0 \mathrm{~h}$ and $\mathrm{SiO}_{2}$ : $24 \mathrm{~h}-3.0$ that the $\mathrm{Si}-\mathrm{O}$ band around $1100 \mathrm{~cm}^{-1}$ grew with aging under $\mathrm{pH}$ 3.0. A similar increase in the IR band intensity was also exhibited for $\mathrm{SiO}_{2}: 24 \mathrm{~h}-9.7$. The band intensity is a measure of the $\mathrm{Si}-\mathrm{O}$ bond density in the macrospheres, and the increase in the $\mathrm{Si}-\mathrm{O}$ band superficially agrees with the gelling observations described in $\$ 3.1$. Yet, the $\mathrm{Si}-\mathrm{O}$ band intensity relative to the $v_{\text {as }}\left(\mathrm{COO}^{-}\right)$and $v_{\mathrm{s}}\left(\mathrm{COO}^{-}\right)$bands due to the alginate molecules was independent of the aging. Therefore, the $1100 \mathrm{~cm}^{-1}$ band growth should not be interpreted by the gelation or increased
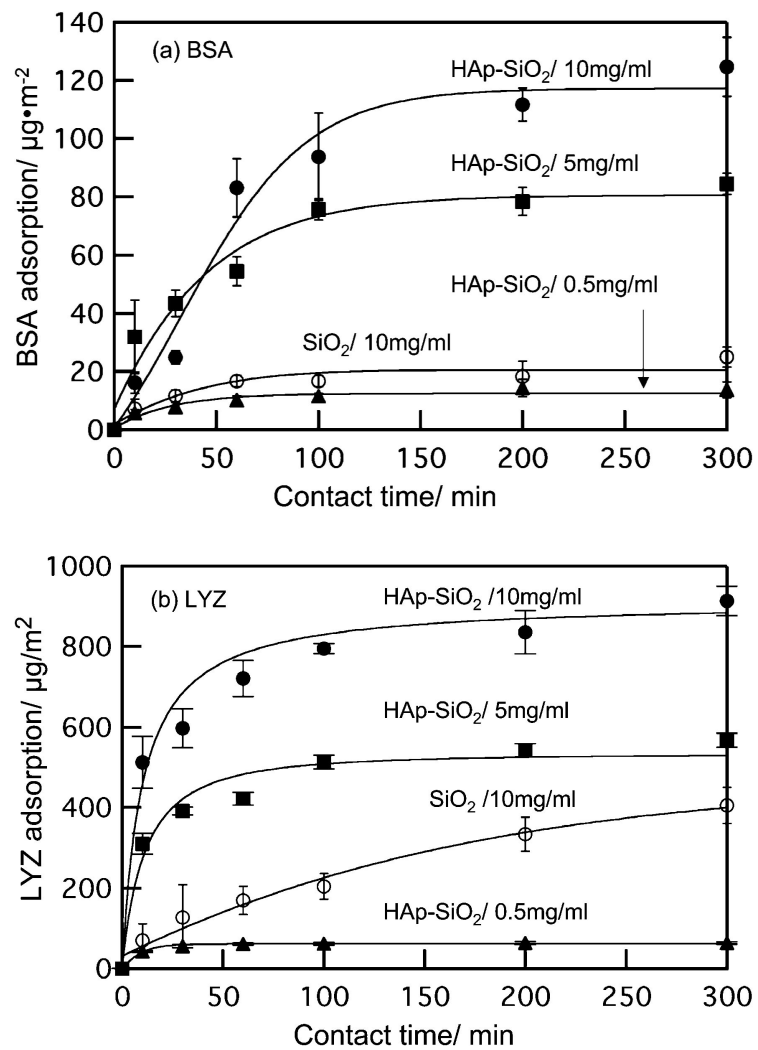

Fig. 6. (a) $\mathrm{BSA}$ and (b) $\mathrm{LYZ}$ adsorption kinetics for the $\mathrm{SiO}_{2}$ (open circles) and $\mathrm{HAp}-\mathrm{SiO}_{2}$ (filled symbols) macrospheres in contact with the solutions of varied protein concentrations. The curves are guides for the eye.

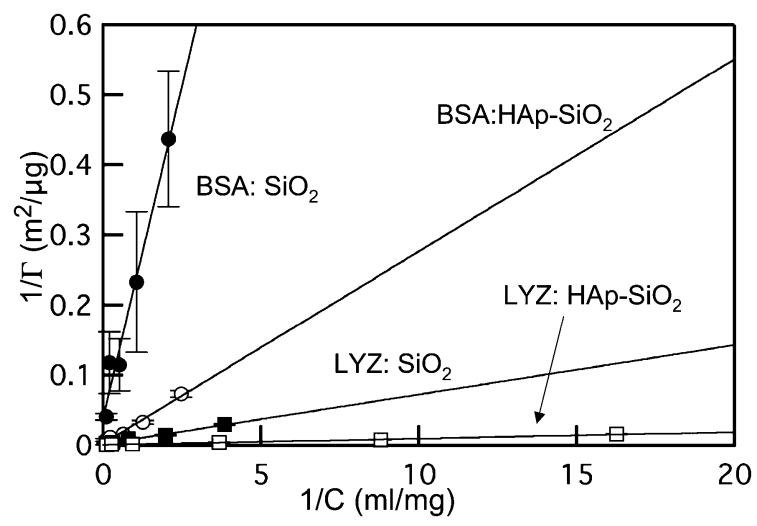

Fig. 7. Langmuir plot [Eq. (2)] of BSA and LYZ adsorption on the $\mathrm{SiO}_{2}$ (filled symbols) and $\mathrm{HAp}-\mathrm{SiO}_{2}$ macrospheres (open symbols).

network density, whereas the increase in the band for the HAp$\mathrm{SiO}_{2}$ was definitely attributed to overlap of the $\nu(\mathrm{P}-\mathrm{O})$ signal from the apatite deposited on the silica macrospheres.

\subsection{Protein adsorption}

\subsubsection{Adsorption simulation from Langmuir model}

Figure 7 shows the data presented in Langmuir type plot, according to Eq. (2). All systems, i.e., BSA absorbed on $\mathrm{SiO}_{2}$ and $\mathrm{HAp}-\mathrm{SiO}_{2}, \mathrm{LYZ}$ adsorbed on $\mathrm{SiO}_{2}$ and $\mathrm{HAp}-\mathrm{SiO}_{2}$ gave good linear correlations between $1 / \Gamma$ and $1 / \mathrm{C}$, with good reliability factor $\mathrm{R}^{2} \sim 0.97$. Table 1 lists the parameters $\Gamma_{\mathrm{m}}$ and $K$, where $\Gamma_{\mathrm{m}}$ represents the amount of relevant adsorbate molecules when they occupy all active sites. Assuming such an extreme case, the 
surface coverage $\theta_{\mathrm{m}}$ (area covered by the proteins/unit surface area) was derived from Eq. (4),

$$
\theta_{\mathrm{m}}=\Gamma_{\mathrm{m}} \cdot\left(N_{\mathrm{A}} / \mathrm{Mw}\right) \cdot S_{\mathrm{p}}
$$

Here, $N_{\mathrm{A}}$ is the Avogadro's number and $\mathrm{Mw}$ is the molar weight of BSA and LYZ, namely, 67200 and 14600 , while $S_{\mathrm{p}}$ is the molecular size: $4 \times 14 \mathrm{~nm}^{2}$ for BSA and $3 \times 3.5 \mathrm{~nm}^{2}$ for LYZ.40) Then, the results were listed in Table 1 . The coverage by BSA was smaller than that by LYZ, in agreement with the amount of adsorption in both mass $\left(\Gamma_{\mathrm{m}}\right)$ and molar $\left(\Gamma_{\mathrm{mol}}\right.$ : the last column of Table 1) basis. In practical cases, a part of the sites available for adsorption remain unoccupied, controlled by the equilibrium.

\subsubsection{Adsorption mechanisms}

It is common to interpret protein adsorption in terms of electrostatic interactions between the proteins and the adsorbent. From the respective isoelectric point (iep): 4.7, 11.1 and 1.8-2.2 for BSA, $\mathrm{LYZ}^{40)}$ and silica, ${ }^{41)}$ negative charges rest on BSA and silica, and a positive charge is on LYZ under physiological conditions, $\mathrm{pH}$ 7.2-7.4. Thus, the electrostatic interaction model can interpret the $\mathrm{LYZ}$ adsorption on the $\mathrm{SiO}_{2}$ macrospheres by 20 times as much mass as that of BSA, indicated in Fig. 6 or by $\Gamma_{\mathrm{m}}$ in Table 1. In molar basis, the LYZ adsorption was $\sim 8$ times as much as the BSA adsorption.

Some complexity was introduced in the $\mathrm{HAp}-\mathrm{SiO}_{2}$ macrospheres because of the apatite crystallites, which have two kinds of crystallographic planes to provide good adsorption sites with varied partial charges. The C-plane and A-plane of the apatite crystal will be positively and negatively charged under $\mathrm{pH}$ 7.4, according to the lattice characteristics: the calcium ions are rich on the former, and the phosphate ions are rich on the latter. The $\mathrm{HAp}-\mathrm{SiO}_{2}$ gave polycrystalline diffractions of apatite in Fig. 2, and the random orientation was confirmed in the SEM image in Fig. 4(c). Thus, it is reasonable that each plane should be exposed to the protein molecules in similar probability, or the protein molecules would have an even chance to find the planes of either charge. That is, the apatite deposition gave the silica macrospheres active sites suitable for BSA for which the electrostatic interactions worked. Actually, the BSA adsorption on the $\mathrm{HAp}-\mathrm{SiO}_{2}$ macrospheres increased by a factor of $\sim 15$. Even LYZ adsorption increased by a factor of $\sim 3.5$. This LYZ case, however, seems strange because the sites with negative charges appeared due to the apatite deposition. The present study failed to identify the orientation of those apatite lattice planes by transmission electron microscopy, and hence, no definite description is possible on the preferably grown plane. Yet, the results at least have indicated that both macrospheres are highly active to adsorb positively charged species, and that the apatite layer on the $\mathrm{HAp}-\mathrm{SiO}_{2}$ macrospheres possesses enhanced ability to adsorbing such species with a negative charge.

Another possible mechanism is trapping molecules in such pores that are large enough to accommodate them. This mechanism is applicable to the $\mathrm{SiO}_{2}$ macrospheres that had mesopores ranging 5 to $20 \mathrm{~nm}$ in size, but is inappropriate to the HAp$\mathrm{SiO}_{2}$ macrospheres without such mesopores. Their SSA (173 $\mathrm{m}^{2} / \mathrm{g}$ ), almost comparable to the $\mathrm{SiO}_{2}$ ones $\left(220 \mathrm{~m}^{2} / \mathrm{g}\right)$, could not be attained if those macrospheres were solid dense spheres. It probably resulted partly from the spaces among the apatite crystallites on the surface layer. Moreover, it seems unlikely that, even if the macrospheres had a larger volume in the mesopore region, the protein molecules would migrate deep into the pores one after another to fill them. The larger values of coverage $\theta_{\mathrm{m}}$ in Table 1 have been derived by assuming that such mesopores should be filled with the protein molecules.
In this regard, another mechanism should work for the present protein adsorption.

\subsubsection{Validity of Langmuir type adsorption}

The protein adsorption on the present silica gel macrospheres would not match the assumptions in deriving Langmuir equation, i.e., a single layer adsorption of gas molecules on a part of the actives sites on a flat surface. Thus, despite that the coverage $\theta_{\mathrm{m}}$ derived from Eq. (4) was smaller than unity in Table 1, or the present macrospheres had surface area enough to adsorb the proteins in a single layer, it is probable that the mode of the protein adsorption in reality did not follow the Langmuir assumptions. It is emphasized that a protein molecule has the groups with a negative $(\mathrm{C}=\mathrm{O}$, or $\mathrm{C}-\mathrm{O})$ or positive partial charge $(-\mathrm{NH}-)$ though it may have either charge in total depending on $\mathrm{pH}$ of the medium in which they are placed. Such charged groups may find good attractive adsorption sites on the adsorbent surface to settle the molecule. It is reasonable to suppose, thus, that a protein molecule still keeps such charges at those groups even after settled on an adsorption site, and that those groups with active charges then should deserve attracting another protein molecules to be adsorbed. That is, once a protein molecule is attached on an adsorption site, new adsorption sites are provided one after another to attain multi-layer adsorption. In this model, the factor to control the total amount of adsorption is the true surface coverage by the molecules that would first come onto the surface.

\section{Conclusions}

Silica gel macrospheres were prepared from water glass as the silica source. The water glass was diluted with $2 \mathrm{M} \mathrm{HCl}$ to adjust $\mathrm{pH}$ of the system, with which sodium alginate solution was mixed. The mixture was added dropwisely to $1 \mathrm{M} \mathrm{CaCl}_{2}$ solution to form macrospheres with $\sim 3$ and $2.6 \mathrm{~mm}$ in diameter. After aged in the $\mathrm{CaCl}_{2}$ solution for $1 \mathrm{~d}\left(\mathrm{SiO}_{2}\right.$ macrospheres), they were soaked in 1:1 (volume) mixture $(\mathrm{pH} 7.8)$ of ethanol and $0.1 \mathrm{M}$ $\mathrm{Na}_{2} \mathrm{HPO}_{4}$, and hydroxyapatite was deposited on their surface (HAp- $\mathrm{SiO}_{2}$ ). According to SEM observation and $\mathrm{N}_{2}$ gas adsorption, the $\mathrm{SiO}_{2}$ macrospheres had smooth surface with a large pore distribution in the mesopore region $(5-20 \mathrm{~nm})$ together with $220 \mathrm{~m}^{2} / \mathrm{g}$ in specific surface area (SSA). The HAp-SiO 2 macrospheres lost those mesopores but had $173 \mathrm{~m}^{2} / \mathrm{g}$ in SSA. FT-IR spectra of the macrospheres exhibited the IR bands characteristic of the component bonds, such as $\mathrm{Si}-\mathrm{O}$ and $\mathrm{P}-\mathrm{O}$. Bovine serum albumin (BSA) and egg lysozyme (LYZ) adsorption on the $\mathrm{SiO}_{2}$ and $\mathrm{HAp}-\mathrm{SiO}_{2}$ macrospheres were measured and analyzed on the basis of Langmuir-type adsorption model. Simple electrostatic interaction between the charged macrosphere surface and protein molecules was predominant, and entrapment of the protein molecules in the pores was partially effective. Yet, the latter was not the case for $\mathrm{HAp}-\mathrm{SiO}_{2}$ without mesopores. A multi-layer adsorption model was proposed, from the presence of both negative and positive charges in a protein molecule.

Acknowledgement Partial financial supports by the Japan Society for Promotion of Science: Bilateral Joint Projects/Seminars (2011-12) and the Wesco Scientific Promotion Foundation (Japan) are gratefully acknowledged.

\section{References}

1) M. Morra, C. Cassinelli, G. Cascardo, A. Carpi, M. Fini, G. Giavaresi and R. Giardino, Biomed. Pharmacother, 58, 418422 (2004).

2) D. E. MacDonald, B. E. Rapuano, N. Deo and M. Stranick, Biomaterials, 25, 3135-3146 (2004). 
3) N. Volpi, Biomaterials, 20, 1359-1363 (1999).

4) M. R. Sierakowski, R. A. Freitas, J. Fujimoto and D. F. S. Petri, Carbohydr. Polym., 49, 167-175 (2002).

5) G. F. Paciotti, D. G. I. Kingston and L. Tamarkin, Drug Dev. Res., 67, 47-54 (2006).

6) W. Eck, G. Craig, A. Sige, G. Ritter, L. J. Old, L. Tang, M. F. Brennan, P. J. Allen and M. D. Mason, ACS Nano, 2, 22632272 (2008).

7) M. C. Tsai and Y. C. Tsai, Sens. Actuators, B, 141, 592-598 (2009).

8) S. T. Tzannis, W. J. M. Hrushesky, P. A. Wood and T. M. Przybycien, J. Colloid Interface Sci., 189, 216-228 (1997).

9) K. H. Staubach, M. Boehme, M. Zimmermann and V. Otto, Transfus. Apheresis Sci., 29, 93-98 (2003).

10) J. Etheve, P. Dejardin and M. Boisslere, Colloids Surf., B, 28, 285-293 (2003).

11) P. Valette, M. Thomas and P. Dejardin, Biomaterials, 20, 16211634 (1999).

12) T. Y. Liu, W. C. Lin, L. Y. Huang, S. Y. Chen and M. C. Yang, Biomaterials, 26, 1437-1444 (2005).

13) T. Asano, K. Tsuru, S. Hayakawa and A. Osaka, Acta Biomater., 4, 1067-1072 (2008).

14) C. F. Mandenius and L. Ljunggren, Biomaterials, 12, 369-373 (1991).

15) C. A. Zittle, Adv. Enzymol, 14, 319-374 (1951).

16) A. Tiselius, S. Hjertén and Ö. Levin, Arch. Biochem. Biophys., 65, 132-155 (1956).

17) S. Hjertén, Biochim. Biophys. Acta, 31, 216-235 (1959).

18) T. Kawasaki, M. Niikura, S. Takahashi and W. Kobayashi, Biochem. Int., 13, 969-982 (1986).

19) R. Murugan and S. Ramakrishna, Acta Biomater., 2, 201-206 (2006).

20) S. Takashima, S. Hayakawa, C. Ohtsuki and A. Osaka, Bioceramics, 9, 217-220 (1997).

21) E. Fujii, M. Ohkubo, K. Tsuru, S. Hayakawa, A. Osaka, K. Kawabata, C. Bonhomme and F. Babonneau, Acta Biomater, 2, 69-74 (2006).

22) S. Hayakawa, K. Ando, K. Tsuru, A. Osaka, E. Fujii, K. Kawabata, C. Bonhomme and F. Babonneau, J. Am. Ceram. Soc., 90, 565-569 (2007).
23) S. Takemoto, Y. Kusudo, K. Tsuru, S. Hayakawa and A. Osaka, J. Biomed. Mater. Res., 69A, 544-551 (2004).

24) K. L. Jones and C. R. O'Melia, J. Membr. Sci., 165, 31-46 (2000).

25) Y.-S. Chen, C.-S. Chang and S.-Y. Suen, J. Membr. Sci., 305, 125-135 (2007).

26) A.-X. Lu, X.-P. Liao, R.-Q. Zhou and B. Shi, Colloids Surf., A, 301, 85-93 (2007)

27) L. Feng and J. D. Andrade, Biomaterials, 15, 324-333 (1994).

28) Z. Ma, Y. Guan and H. Liu, J. Magn. Magn. Mater., 301, 469477 (2006).

29) Y. Yu and Y. Sun, J. Chromatogr. A, 855, 129-136 (1999).

30) K. Kandori, S. Sawai, Y. Yamamoto, H. Sito and T. Ishikawa, Colloids Surf., 68, 283-289 (1992).

31) S. Sudheer Khan, P. Srivatsan, N. Vaishnavi, A. Mukerjee and N. Chandrasekaran, J. Hazard. Mater., 192, 299-306 (2011).

32) T. Berlind, P. Tengvall, L. Hultman and H. Arwin, Acta Biomater, 7, 1369-1378 (2011).

33) D. Klint and H. Eriksson, Protein Expr. Purif., 10, 247-255 (1997).

34) C. W. Suh, M. Y. Kim, J. B. Choo, J. K. Kim, H. K. Kim and E. K. Lee, J. Biotechnol., 112, 267-277 (2004).

35) W.-H. Huang, D. E. Day, K. Kittiratanapiboon and M. N. Rahaman, J. Mater. Sci.: Mater. Med., 17, 583-596 (2006).

36) B. K. Coltrain, S. M. Melpolder and J. M. Salva, Proc. IVth Internatl. Conf. Ultrastructure Processing of Ceramics, Glasses, and Composites, Feb. 19-24, 1989: cited as Ref. 57 in Chapter 3: Hydrolysis and Condensation II: Silicates, in C. J. Brinker and G. W. Scherer, "Sol-Gel Science: the Physics and Chemistry of Sol-Gel Processing," Academic Press, San Diego (1990).

37) A. Bigi, G. Cojazzi, S. Panzavolta, A. Ripamonti, N. Roveri, M. Romanello, K. Noris Suarez and L. Moro, J. Inorg. Biochem., 68, 45-51 (1997).

38) R. Z. LeGeros, Nature, 206, 403-404 (1965).

39) B. O. Fowler, Inorg. Chem., 13, 207-213 (1974).

40) K. Kandori, S. Mizumoto, S. Toshima, M. Fukusumi and Y. Morisada, J. Phys. Chem. B, 113, 11016-11022 (2009).

41) G. A. Parks, Chem. Rev., 65, 177-198 (1965). 